\title{
'The Hand on the Doorknob': Visit Agenda Setting by Complex Patients and Their Primary Care Physicians
}

\author{
Christine P. Kowalski, MPH, Deanna B. McQuillan, MA, Neetu Chawla, PhD, MPH, \\ Courtney Lyles, PhD, Andrea Altschuler, PhD, Connie S. Uratsu, RN, MS, PHN, \\ Elizabeth A. Bayliss, MD, Michele Heisler, MD, MPA, and \\ Richard W. Grant, MD, MPH
}

Background: Choosing which issues to discuss in the limited time available during primary care visits is an important task for complex patients with chronic conditions.

Design, Setting, and Participants: We conducted sequential interviews with complex patients $(\mathrm{n}=$ 40) and their primary care physicians $(n=17)$ from 3 different health systems to investigate how patients and physicians prepare for visits, how visit agendas are determined, and how discussion priorities are established during time-limited visits.

Key Results: Visit flow and alignment were enhanced when both patients and physicians were effectively prepared before the visit, when the patient brought up highest-priority items first, the physician and patient worked together at the beginning of the visit to establish the visit agenda, and other team members contributed to agenda setting. A range of factors were identified that undermined the ability of patient and physicians to establish an efficient working agenda: the most prominent were time pressure and short visit lengths, but also included differing visit expectations, patient hesitancy to bring up embarrassing concerns, electronic medical record/documentation requirements, differences balancing current symptoms versus future medical risk, nonactionable items, differing philosophies about medications and lifestyle interventions, and difficulty by patients in prioritizing their top concerns.

Conclusions: Primary care patients and their physicians adopt a range of different strategies to address the time constraints during visits. The primary factor that supported well-aligned visits was the ability for patients and physicians to proactively negotiate the visit agenda at the beginning of the visit. Efforts to optimize care within time-constrained systems should focus on helping patients more effectively prepare for visits. Physicians should ask for the patient's agenda early, explain visit parameters, establish a reasonable number of concerns that can be discussed, and collaborate on a plan to deal with concerns that cannot be addressed during the visit. (J Am Board Fam Med 2018;31:29-37.)

Keywords: Chronic Disease, Documentation, Lifestyle, Primary Health Care, Primary Care Physicians, Risk

Primary care has become increasingly complex. With the overall aging of the primary care population, many patients have multiple concurrent conditions including social or economic stressors that affect their health. ${ }^{1,2}$ In parallel with this trend of greater patient complexity, an increasing focus on practice guidelines and performance measurement has significantly added to the number of

This article was externally peer reviewed.

Submitted 19 April 2017; revised 30 August 2017; accepted 23 September 2017. items that primary care physicians (PCPs) are expected to address during time-limited visits. ${ }^{3,4} \mathrm{In}$ this context of too much to do in too little time, the

From the Center for Clinical Management Research, VA Ann Arbor Healthcare System, Ann Arbor, MI (CPK, $\mathrm{MH})$; Institute for Health Research, Kaiser Permanente Colorado, Denver, CO (DBM, EAB); Division of Research, Kaiser Permanente-Northern California, Oakland, CA (NC, AA, CSU, RWG); Center for Vulnerable Populations, University of California-San Francisco, San Francisco (CL); Department of Family Medicine, University of Colorado School of Medicine, Aurora (EAB); Department of Internal Medicine, University of Michigan, Ann Arbor (MH). 
Figure 1. Schematic diagram of factors influencing patient-provider visit agenda alignment. PCP, primary care physicians.

\begin{tabular}{|c|c|c|c|}
\hline $\begin{array}{l}\text { Patient's Perspective } \\
\text { Visit Preparation } \\
\text { High level of preparation } \\
\text { - Thought about visit in advance } \\
\text { Made lists, collected data logs, } \\
\text { conducted research, talked to } \\
\text { family members, emailed } \\
\text { physician } \\
\text { Low level of preparation } \\
\text { Did not give much thought to } \\
\text { what they wanted to discuss at } \\
\text { the visit in advance } \\
\text { Did not bring a list } \\
\text { Defined preparation differently } \\
\text { in some cases (completing } \\
\text { bloodwork prior to visit, or not } \\
\text { drinking caffeine that morning) } \\
\text { Factors that influence preparation } \\
\text { and prioritization } \\
\text { What is most bothersome / } \\
\text { interfering with quality of life } \\
\text { The most 'dangerous' } \\
\text { What is the newest } \\
\text { Let the PCP set the priorities } \\
\text { Unable to prioritize }\end{array}$ & $\begin{array}{l}\text { Factors contributing to misalignment } \\
\text { - Short visit lengths \& time pressure } \\
\text { - Differing visit expectations } \\
\text { - Patient hesitancy to bring up } \\
\text { embarrassing concerns } \\
\text { - Electronic medical record and } \\
\text { documentation requirements } \\
\text { - Balancing current symptoms vs. future } \\
\text { medical risk } \\
\text { - Role of non-actionable items } \\
\text { - Differing philosophies regarding } \\
\text { medications vs. lifestyle interventions } \\
\text { - Difficulty by patients prioritizing top } \\
\text { concerns (narrowing list) resulting in } \\
\text { too many items to cover in one visit }\end{array}$ & $\begin{array}{l}\text { Factors contributing to alignment } \\
\text { - Effective patient pre-visit preparation } \\
\text { including prioritization and limiting of } \\
\text { patient list to the length of one visit } \\
\text { - Pre-visit preparation by the PCP } \\
\text { - Patient reports highest priority item } \\
\text { - Nurses or medical assistant help set } \\
\text { and manage visit agendas } \\
\text { - Physician discusses with patients and } \\
\text { decides whether to run over allotted } \\
\text { time or have items fall off this visit } \\
\text { agenda to another scheduled visit } \\
\text { - Patient and physician are able to } \\
\text { proactively negotiate visit agenda } \\
\text { early }\end{array}$ & 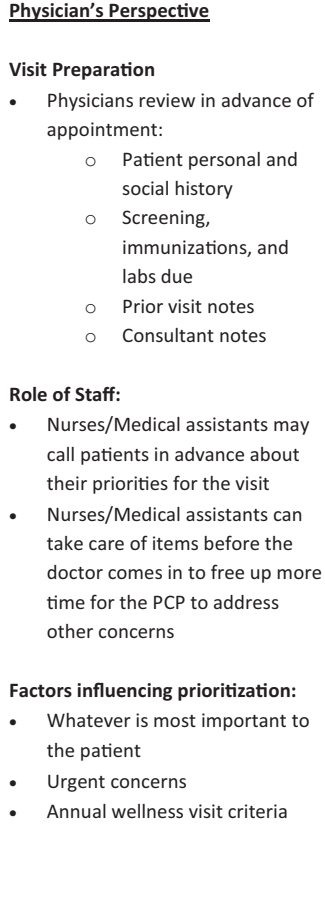 \\
\hline
\end{tabular}

ability of patients and their physicians to work together to identify and align priorities for a visit may represent a critical, underdeveloped skill necessary for effective primary care. ${ }^{5}$ Such effective collaboration is of particular importance for complex patients due to the many different questions and concerns these patients may have about their health care.

Prior studies have found that complex patients and their physicians agreed on the top visit priorities up to two thirds of the time. ${ }^{6,7}$ When patients and physicians differed, patients typically prioritized discussing their current symptoms whereas physicians prioritized guideline-based prevention and chronic disease management. ${ }^{7}$ Research on patients with diabetes has shown that when patient-

Funding: Research reported in this publication was funded through a Patient-Centered Outcomes Research Institute (PCORI) Award (CDR-1403-11992). The views, statements, and opinions in this article are solely the responsibility of the authors and do not necessarily represent the views of the PCORI, its Board of Governors, or Methodology Committee.

Conflict of interest: none declared.

Corresponding author: Richard W. Grant, MD, MPH, Kaiser Permanente, Division of Research, 2000 Broadway, Oakland, CA 94612 (E-mail: Richard.W.Grant@KP.org). physician communication is suboptimal, patients have worse adherence and poorer clinical outcomes. ${ }^{8-10}$ To date, there has been little research investigating how patients and physicians prepare for, prioritize, and align visit agendas.

Given that effective primary care requires collaboration between patients and physicians, further insight into the barriers and facilitators to aligning patient and physician visit priorities may be helpful for efforts to improve communication during timelimited visits. To address this need, we separately interviewed complex patients and their PCPs to: 1) examine how patients and physicians prepared for upcoming visits; 2) gain further insight into how agendas are set during visits; and 3) identify factors that facilitate or impede alignment of visit agendas. We also developed a conceptual model (Figure 1) to better understand the factors that influence patient and provider visit alignment.

\section{Methods}

\section{Study Sample and Design}

We conducted a longitudinal, qualitative study in 3 geographically diverse health care settings: Kaiser Permanente-Northern California; Kaiser Perma- 
nente-Colorado; and University of Michigan-Ann Arbor. Study sites included both hospital-based and community-based practices serving a wide range of patient populations. Data were collected between January and December 2015. In-person interviews lasted approximately 45 minutes. Each interview was digitally recorded and transcribed verbatim. Institutional review boards from each of the 3 sites provided approval for this study.

PCPs (11 internal medicine and 6 family medicine) were recruited from each of the clinics and asked to identify and approve subsequent recruitment of their complex adult patients, defined as having 2 or more chronic conditions. Patients from each physician panel and the physicians themselves were continually recruited until qualitative data discovery had reached saturation.

The interviews proceeded sequentially in a longitudinal design with patient then PCP then patient again; patient priorities were shared with the PCP after the PCP listed their priorities for each patient. The interviews with the patients were most often collected in the weeks before a scheduled visit or in the clinic on the same day of their visit before being seen. Discussions with physicians occurred after the patient's visit, generally the same day or in the weeks following. We reinterviewed patients several weeks later to explore with them their thoughts about how their provider's priorities may have differed from their own.

\section{Conceptual Model}

Our patient interview guide was developed collaboratively across the 3 study sites and included the following qualitative domains: patient involvement with decision making about their care; patient strategies used for visit preparation; process of agenda selection; structure of the last primary care visit, including the ebb and flow of the visit and content covered; barriers to addressing patient agenda items; and identification of the patients' top 3 priorities for their upcoming PCP visit. After the interviews were completed we developed a conceptual framework (Figure 1) based on the interview data in which patients and physicians come in to the visit with their own unique perspectives for what occurs during the visit.

We developed the physician interview guide based on a review of the literature for physician and patient communication and prioritization. The guide included the following domains identified before the interviews: process of eliciting patient concerns and priorities; barriers to covering all patient concerns; barriers and facilitators to alignment of priorities; and top 3 priorities for upcoming visits. We also obtained permission from each patient to share their upcoming visit priorities with their PCPs. We then elicited the PCP's own priorities for that patient's visit to gain more specific insight into how patients and their physicians differed in their perceived visit priorities.

\section{Qualitative Methods}

We analyzed transcripts from the patient and physician interviews using data-derived directed content analysis. ${ }^{11-13}$ After each interview, interviewers $(\mathrm{PhD}$ researchers with expertise in qualitative methods [CK, NC, CL] working in collaboration with physician researchers trained in primary care [MH, EAB, RWG]) created detailed qualitative summaries based on the interview content. Then, each team member read through the summaries and using an iterative process, we developed a preliminary coding schema. Data analysis started with immersion in the data to obtain a sense of the whole, followed by making labels for initial codes that emerged as reflective of more than $1 \mathrm{key}$ thought. Subsequently each team member independently coded transcripts, and then met as a group to discuss and reconcile codes, identify emergent themes, and resolve discrepancies through consensus.

Each interviewer coded their own transcripts and produced comprehensive coding reports for each of the key themes. The main coding team (CK, DBM, NC), consisting of 1 researcher from each site, met biweekly to review and compare coding reports and key quotes across sites. The overall research team, including all the authors, met monthly over a period of 12 months to discuss and finalize the themes. Any disagreements were resolved through consensus discussion and by returning to the original data for confirmation. The themes were then compared within and between sites to better understand similarities and differences.

\section{Results}

We interviewed 40 patients (23 women, 17 men; mean age, 69.4 years, range, 37-92 years) and 17 physicians (12 women, 5 men) across the 3 study 
sites. Four of the 17 physicians had 1 patient in the study, 6 had 2 patients, 2 had 3 patients, and 4 physicians had 1 patient. Patients had a wide range of health conditions including diabetes, heart disease, depression, and arthritis.

\section{Patient and Physician Preparation for Upcoming Visits}

The majority of patients reported some form of previsit preparation, including written lists of concerns (eg, handwritten, smart phone), emails to physicians, information seeking about conditions or medications, or discussion of priorities with family members/spouses. In addition to lists, well-prepared patients brought data logs (eg, blood pressure readings, glucose levels) in printouts or as data in an electronic device such as a tablet or cell phone.

Patients commonly noted 2 main reasons for previsit preparation. The first was to ensure they did not forget or were not too intimidated to mention something (Quote 1, Table 1). A second reason was to make sure that their agenda was incorporated into the discussion with PCPs so that mutually developed strategies were employed to work toward patient health goals. Other patients did not prepare for their visits with PCPs, most commonly because they felt that the physician's agenda should drive the visit or due to the perception that there was not much wrong with their health.

Most PCPs reported a uniform method of previsit preparation for all patient encounters; they reviewed their patient's previous clinical notes in advance and recent specialist notes and labs to remind them about what was discussed and what items the patient may be due for (eg, vaccines, lab screenings, mammograms) or that require followup. Physicians spent time preparing so that they would have more time to listen to patients and build rapport (Quote 2).

Physicians generally appreciated when the patient was organized and prepared with a list, but with caveats around list length and expectation setting (quote 3). Physicians also expressed concern about patients with very lengthy lists (quote 4). Physicians preferred that the patient bring up items during a visit, as opposed to contacting them afterward about a forgotten item. Conversely, some PCPs worried about unmet expectations, stating that just because an item is on a patient's list does not mean it will get covered.

\section{Insights into Agenda Setting}

Patient agenda-setting strategies typically fell into 3 types: 1) letting the provider set the priorities (Quote 5); 2) prioritizing based on symptoms, sometimes expressed as what was interfering the most with their quality of life (Quote 6); and 3) prioritizing based on creating a mutual agenda (Quote 7).

Three key themes emerged regarding how PCPs set their visit agendas: 1 ) prioritizing the most important of the patient's listed concerns, 2) prioritizing items they considered urgent and/or dangerous, and 3) acknowledging that "realistic prioritizing" meant some items would "fall off" the agenda. One PCP described joint prioritization of visit topics and agenda setting as an interaction that gets easier in time, but can be very difficult in the beginning (Quote 8). Another PCP described how his view of patient lists has changed over the years (Quote 9).

\section{Factors that Facilitate or Impede Alignment of Visit Agendas}

Both patients and physicians acknowledged that effective patient and physician previsit preparation was an important facilitator contributing to alignment. Both also agreed that both the need to prioritize topics for discussion and early joint-agenda setting were important facilitators (see Quotes 3, 7, 8 , and 9). To help prevent patient delays in raising stigmatizing concerns, some physicians thought it would be useful to reassure patients about that safety of raising such concerns (Quote 10).

Patients noted 2 major barriers to alignment of priorities: 1) short visit lengths, and 2) difficulty in raising sensitive concerns. While some patients described having enough time with their PCPs to address their needs, others felt that short visit lengths made it difficult for them to communicate their priorities. For example, 1 patient described a list of 5 things that she wanted to address in the visit but could not (Quote 11). Similarly, another patient described not asking about an immediate health concern due to lack of time with the PCP (Quote 12).

Potentially embarrassing or stigmatizing concerns were another source of misalignment that affected visit flow because patients described waiting until the very end of the visit to raise these. Examples of these types of concerns provided by our patients included sexual dysfunction, blood in 
Table 1. Illustrative Quotes from a Qualitative Study of Preparation, Prioritization, and Agenda Setting by Complex Patients and their Physicians during Primary Care Visits

\begin{tabular}{|c|c|c|}
\hline Quote No. & Interviewee Type & Quotation \\
\hline \multicolumn{3}{|c|}{$\begin{array}{l}\text { Primary care visit } \\
\text { preparation }\end{array}$} \\
\hline 1 & Patient & $\begin{array}{l}\text { "You don't think about that when you are right in that room. It's that white coat } \\
\text { syndrome, you kind of freeze up a little." }\end{array}$ \\
\hline 2 & Physician & $\begin{array}{l}\text { "You're able to listen to them better because you've got everything ready there } \\
\text { for you." }\end{array}$ \\
\hline 3 & Physician & $\begin{array}{l}\text { "Sometimes I'll have patients throw something at you as you're trying to walk out } \\
\text { the door; you think you're all done and then, 'Oh, there was one more thing, I } \\
\text { will actually address it the first or second time it happens and say, 'What you } \\
\text { can do to make things go better and make this visit less stressful is to bring in a } \\
\text { list, write it ahead of time so that you remember everything you want me to } \\
\text { deal with, and then we'll be able to get through everything." }\end{array}$ \\
\hline 4 & Physician & $\begin{array}{l}\text { "Because I know the more they have on their list, even though I try to address it, } \\
\text { the less I think I'm giving them what they need, because there's just so much . } \\
\text {.." }\end{array}$ \\
\hline \multicolumn{3}{|c|}{$\begin{array}{l}\text { Insights into agenda } \\
\text { setting for } \\
\text { primary care } \\
\text { visits for } \\
\text { medically } \\
\text { complicated } \\
\text { patients }\end{array}$} \\
\hline 5 & Patient & $\begin{array}{l}\text { "I basically let him [doctor] set the priorities because there's certain things that } \\
\text { are more critical than others, like my blood pressure, he really likes to make } \\
\text { sure that that's well controlled." }\end{array}$ \\
\hline 6 & Patient & "Something I couldn't take or stand." \\
\hline 7 & Patient & $\begin{array}{l}\text { "I say [to myself], 'Okay, how are you going to prioritize what you're going to } \\
\text { say and then what are you're going to obey? because if I'm paying } \$ 93 \text { a visit I } \\
\text { want to be compliant, but on things that I feel, both of us feel are important." }\end{array}$ \\
\hline 8 & Physician & $\begin{array}{l}\text { "I've been doing this for } 20 \text { years and at the beginning this was very difficult- } \\
\text { because patients often come in with a very long list and you need to be able to } \\
\text { learn to help them and yourself sort out what are the most important things } \\
\text { that need to be talked about today." }\end{array}$ \\
\hline 9 & Physician & $\begin{array}{l}\text { "When I first started out in medicine, I hated lists. I love lists now. The best list } \\
\text { is one you can take from the patient yourself and look at, but even if they just } \\
\text { have a list because then they don't have that 'by the way' as you walk out the } \\
\text { door, 'I'm having rectal bleeding, or chest pain, or shortness of breath." }\end{array}$ \\
\hline \multicolumn{3}{|c|}{$\begin{array}{l}\text { Factors that facilitate } \\
\text { or impede } \\
\text { alignment of } \\
\text { visit agendas }\end{array}$} \\
\hline 10 & Physician & $\begin{array}{l}\text { "Don't be embarrassed, no matter what it is, your doctor has heard everything } \\
\text { and this room is private and anything you say and hear is privileged } \\
\text { information." }\end{array}$ \\
\hline 11 & Physician & $\begin{array}{l}\text { "I don't burden those things on Dr. }[\mathrm{PCP}] . . . \text { He has his agenda. I have my } \\
\text { agenda. ... Time is not really long . . . I think at most } 15 \text { minutes. By the } \\
\text { time [we] greet each other } 5 \text { minutes of that is gone. I never had a chance to } \\
\text { tell him }[\mathrm{PCP}] \text { all I told you because we just don't have that kind of time." }\end{array}$ \\
\hline 12 & Patient & $\begin{array}{l}\text { "Well, even today because it was only } 15 \text { minutes I did not ask about my } \\
\text { [concern that] . . I can't lift my arm that high and I need physical therapy." }\end{array}$ \\
\hline 13 & Patient & $\begin{array}{l}\text { "Well, depressed. I'm depressed as hell. I mean, really bad, lately. And... } \\
\text { [Interviewer: Do you tell [PCP] about that?] No. I didn't tell her that. } \\
\text { [Interviewer: Okay. How come?] I don't know." }\end{array}$ \\
\hline 14 & Physician & $\begin{array}{l}\text { "I think we have too many patients ... all of us who are actually doing this work } \\
\text { are going to be completely stressed out. People are sicker, they're living longer, } \\
\text { they're pushed out of the hospital sooner and there's this kind of sense that it } \\
\text { all falls down on the primary care doctor." }\end{array}$ \\
\hline
\end{tabular}


Table 1. Continued

\begin{tabular}{|c|c|c|}
\hline Quote No. & Interviewee Type & Quotation \\
\hline 15 & Patient & $\begin{array}{l}\text { "One of the things that is so great about him is that he has never told me that he } \\
\text { is too busy to talk to me. If it takes } 45 \text { minutes, then he will." }\end{array}$ \\
\hline 16 & Patient & $\begin{array}{l}\text { "I am aware of his schedule, but sometimes, just between you and me, I'll creep } \\
\text { over into the next poor soul's minutes slightly. I'm aware of that, but if we're } \\
\text { into a discussion and I'm getting the information I need . . " }\end{array}$ \\
\hline 17 & Physician & $\begin{array}{l}\text { "When I started, we had paper charts to take notes in, and so you'd see a patient, } \\
\text { you'd be writing their note while you talk to them, which isn't very distracting } \\
\text { to you or the patient and then you would hand them their check-out stuff and } \\
\text { you were done. So I worked at work and I lived at home, and then through the } \\
\text { years, now everything has to be on the EMR, that takes longer, everybody } \\
\text { knows it takes longer." }\end{array}$ \\
\hline 18 & Physician & $\begin{array}{l}\text { "I feel strongly that the computer ought not to be a focus point during the } \\
\text { interaction, so I have my notes in advance and one of the reasons I have always } \\
\text { done that is so I don't look things up on the computer . . . I'm not saying, } \\
\text { "Well let's find out what the cardiologist said when they saw you, and let's } \\
\text { check to see if you're due for any immunizations," I've done all that in advance, } \\
\text { so I don't have to interact with the computer for that purpose, and I don't type } \\
\text { things while I'm talking to people." }\end{array}$ \\
\hline 19 & Patient & $\begin{array}{l}\text { "They [other doctors] have to go into the electronic medical record and he does } \\
\text { a really good job of not doing that when the patient's in the room. You know, } \\
\text { the physicians have to work on some of that themselves and some of them will } \\
\text { do it right when the patient's sitting there because of time constraints, but he } \\
\text { does his all on his own time. He told me that he feels it's really important to } \\
\text { have eye contact and have a regular conversation with the patient." }\end{array}$ \\
\hline 20 & Physician & $\begin{array}{l}\text { "It took forever to get to [her request]: 'I just need you to write a letter and then } \\
\text { they waive the admission fee. . .' And I was like, 'Gosh, if you could have just } \\
\text { said that I would have been typing the letter while you were talking about } \\
\text { things.' }\end{array}$ \\
\hline 21 & Physician & $\begin{array}{l}\text { "There's always the, when you think you're done and the hand on the door, 'By } \\
\text { the way, you know, I've had chest pain or I'm really depressed.' Those are } \\
\text { usually the ones they sometimes are reluctant to talk about but really want to } \\
\text { talk about . . . there's always a surprise." }\end{array}$ \\
\hline
\end{tabular}

EMR, electronic medical record; PCP, primary care physician.

stool, anxiety, panic attacks, depression, suicidal ideation, and housing issues. Sometimes such concerns did not get addressed at all (quote 13).

Physicians described short visit lengths, added burden of computer documentation, differences in relative ranking of condition importance (and mismatched views about the number of concerns that can be addressed in a single visit), nonactionable items, patient hesitancy to bring up embarrassing or stigmatizing concerns, and differences related to medications versus lifestyle management as important barriers to aligning priorities with their complex patients.

Physicians agreed with patients on the challenges of limited visit times and the need to establish priorities from longer lists of potential concerns. Many physicians described experiencing stress surrounding the process for setting priorities and time limitations in an increasingly complex primary care patient population (Quote 14).

Despite the reported time constraints, several physicians reported that they went over the allotted appointment time to address all the patients' concerns. Patients valued knowing that their physician would take extra time with them when necessary, realizing this may mean that the physician would be running behind in clinic at times (Quote 15). Patients also expressed awareness that if they were going over their allocated time, another patient would be affected (Quote 16).

Physicians expressed concerns over the added burden of necessary computer documentation, for example, electronic medical record (EMR), within time constraints (Quote 17). Some physicians discussed how they attempt to overcome the EMR focus during their patient visits (Quote 18). A patient in the corresponding dyad to that PCP independently noted that he really appreciates how his PCP reviews his chart before he arrives for the visit and does not enter things into the EMR while speaking to him (Quote 19).

Another frequent source of misalignment between patient and physician involved differences in 
Tips from physicians to patients:

1) Bring a thoughtful list of your concerns and questions to your visit.

2) Try to prioritize your list and bring up the issues most urgent or important for you at the beginning of the visit.

3) Do not be shy, your doctor has heard everything before and they are here to help you. Try not to save issues that you may perceive as embarrassing or scary for the end of the visit.

4) Ask any questions that you have during your visit.

5) If you have any remaining concerns when the visit is closing, make a plan with your physician for how to address them later. Tips from patients to physicians:

1) Ask for the patients' agenda early.

2) Explain how many items and the types of concerns that can be covered during a typical visit.

3) Make a plan for concerns that remain after the visit.

4) Leave sufficient space for patients to raise sensitive or private concerns.

5) Be clear about when issues feel "unactionable" or explored as much as possible.

relative ranking of condition importance, which generally reflected a greater patient focus on current symptoms compared with the physician tendency to prioritize medical risk reduction. For example, 1 patient receiving end-of-life treatment for renal failure wanted to focus on what the physician considered the comparatively less important issue of toenail fungus. Another patient prioritized his eczema and felt his heart was fine, whereas his physician prioritized cardiovascular risk reduction due to his past history of a heart attack. Some patients felt that all the items on their list were important and they could not rank 1 over another, while other patients preferred to let their physician prioritize.

Items perceived by physicians as "nonactionable" tended to create a barrier to effective agenda coordination. PCPs reported that a key goal while listening to patient information was to determine actionable steps for patient care. For example, 1 physician described frustration with receiving excessive, nonactionable information (Quote 20). "Nonactionable" items could also include existing patient concerns that had been previously addressed. For example, 1 patient had listed her dizziness as a top priority, while her physician reported that this symptom had been extensively evaluated in the past and that no further management actions were planned.

Patient delays in raising concerns (or physician inability to elicit them early in the visit) led to the problem of new issues coming to light at the end of the visit (Quote 21). One final example of potential misalignment was differences related to medications versus lifestyle management. One patient described how she felt her PCP was "pushing" med- ication to manage her elevated blood pressure and early diabetes; however, she preferred to focus on a strict diet and exercise plan to avoid having to take additional medications.

\section{Discussion}

Through qualitative interviews with complex patients and their PCPs, we found that visit preparation and alignment of visit agendas were critical concepts influencing primary care visit interactions. Time constraints require patients and physicians to implement proactive strategies early in the visit to better manage their limited time together. When this process was not well aligned, interactions during visits tend to suffer. In Table 2, we summarize simple advice from physicians to patients and from patients to physicians.

Many of the complex and typically older adults in our study expressed some difficulty in being able to visit priorities. Prior quantitative research has shown that the initial starting point for a visit has a very large impact on the subsequent content of that visit. For example, 1 study using videotaped encounters revealed that the first item addressed in the primary care visit received the bulk of the subsequent attention for that visit. ${ }^{14}$ Prior studies have also shown that many patients tend to leave important concerns until the end of the encounter, adding to the time pressure of the visit. ${ }^{15-17} \mathrm{We}$ found that many these delayed or deferred concerns were considered embarrassing or stigmatizing by the patients. This barrier has been described in other studies as "unvoiced concerns" and "disclosure deliberations" 18,19 that often include issues related to sexual activity, depression or anxiety, financial or domestic problems, or physical function. ${ }^{18}$ 
Our results extend prior research on the importance of list making. ${ }^{20} \mathrm{We}$ found that truly effective previsit preparation required an important additional step in which patients effectively prioritize and limit the length of their lists to fit within the constraints of a single visit. Moving from simple list making to active prioritization is an advanced skill. ${ }^{21}$ Even among patients who make lists, we found several examples of persistent misalignment that could potentially be alleviated and reflected the broader theme of differences between patients and physician perspectives. Many patients focused on current symptoms whereas physicians highlighted reduction of future medical risk. Similarly, several patients preferred lifestyle interventions and resisted medication prescriptions. ${ }^{22,23}$ Efforts to educate both patients and physicians on their counterpart's perspectives (Table 2) may help both to more quickly and effectively negotiate the visit agenda.

One novel issue identified in our study underscoring differences between patients and physicians was the concept of "nonactionable" items. These items, while important for understanding the patient's current circumstances, did not require any specific action on the part of physicians. In the context of needing to make best use of limited time, several physicians preferred that patient lists highlight items that could be directly addressed.

Our findings must be viewed in the context of our study design. Because this was a qualitative study, our results are better suited for hypothesis generation and cannot be used to infer causality. Moreover, patient and provider interviews with research staff may not fully capture the "true" interaction that occurs during visits. We did not note any significant thematic differences between the internal medicine and family medicine physicians, although we did not systematically explore this. Finally, while interviews were conducted in a wide range of geographic locations, all patients were insured and English speaking, and thus results may not be generalizable to other settings and patients.

Based on our results, we suggest 3 potentially strategies for improving primary care. The first is patient education on how to prepare for visits. Such education should go beyond recommendations for list making to developing skills related to prioritization, engagement in care planning, and disclosure. The second is physician training: Physicians, too, could benefit from early career training in how to work with patients to set up a visit agenda and how to balance individual patient needs with clinical efficiency during busy clinic days. The third is greater involvement of other care team members and family. This strategy is consistent with the Patient-Centered Medical Home model ${ }^{24}$ and Wagner's Chronic Care model ${ }^{25}$, both of which describe a team-based approach to the primary care of complex patients. ${ }^{26}$ Making significant changes to our current system is a major long-term endeavor. Our findings suggest initial efforts focused on patient and provider training related to visit preparation and agenda setting may help improve the complex process of primary care.

To see this article online, please go to: bttp://jabfm.org/content/ 31/1/29.full.

\section{References}

1. Vogeli C, Shields AE, Lee TA, et al. Multiple chronic conditions: Prevalence, health consequences, and implications for quality, care management, and costs. J Gen Intern Med 2007;22(Suppl 3):391-5.

2. Wolff JL, Starfield B, Anderson G. Prevalence, expenditures, and complications of multiple chronic conditions in the elderly. Arch Intern Med 2002;162: 2269-76.

3. Abbo ED, Zhang Q, Zelder M, Huang ES. The increasing number of clinical items addressed during the time of adult primary care visits. J Gen Intern Med 2008;23:2058-65.

4. Pollak KI, Krause KM, Yarnall KS, Gradison M, Michener JL, Østbye T. Estimated time spent on preventive services by primary care physicians. BMC Health Serv Res 2008;8:245.

5. Grant RW, Adams AS, Bayliss EA, Heisler M. Establishing visit priorities for complex patients: A summary of the literature and conceptual model to guide innovative interventions. Healthcare 2013; 1(3-4):117-22.

6. Tomsik PE, Witt AM, Raddock ML, et al. How well do physician and patient visit priorities align? J Fam Pract 2014;63(8):E8-E13.

7. Zulman DM, Kerr EA, Hofer TP, Heisler M, Zikmund-Fisher BJ. Patient-provider concordance in the prioritization of health conditions among hypertensive diabetes patients. J Gen Intern Med 2010;25: 408-14.

8. Ratanawongsa N, Karter AJ, Parker MM, et al. Communication and medication refill adherence: The Diabetes Study of Northern California. JAMA Intern Med 2013;173:210-8.

9. Heisler M, Bouknight RR, Hayward RA, Smith DM, Kerr EA. The relative importance of physician communication, participatory decision making, and pa- 
tient understanding in diabetes self-management. J Gen Intern Med 2002;17:243-52.

10. Peek ME, Wilson SC, Gorawara-Bhat R, OdomsYoung A, Quinn MT, Chin MH. Barriers and facilitators to shared decision-making among AfricanAmericans with diabetes. J Gen Intern Med 2009;24: 1135-9.

11. Mason J. Qualitative researching. Thousand Oaks, CA: Sage Publications; 2002.

12. Patton MQ. Enhancing the quality and credibility of qualitative analysis. Health Serv Res 1999;34(5 Pt 2):1189-208.

13. Hsieh HF, Shannon SE. Three approaches to qualitative content analysis. Qual Health Res 2005;15: 1277-88.

14. Tai-Seale M, McGuire TG, Zhang W. Time allocation in primary care office visits. Health Serv Res 2007;42:1871-94.

15. White J, Levinson W, Roter D. "Oh, by the way ...": The closing moments of the medical visit. J Gen Intern Med 1994;9:24-8.

16. White JC, Rosson C, Christensen J, Hart R, Levinson W. Wrapping things up: A qualitative analysis of the closing moments of the medical visit. Patient Educ Couns 1997;30:155-65.

17. Arnold CL, Coran JJ, Hagen MG. Revisiting patient communication training: An updated needs assessment and the AGENDA model. Patient Educ Couns 2012;88:399-405.

18. Sankar P, Jones NL. To tell or not to tell: Primary care patients' disclosure deliberations. Archiv Intern Med 2005;165:2378-83.
19. Barry CA, Bradley CP, Britten N, Stevenson FA, Barber N. Patients' unvoiced agendas in general practice consultations: Qualitative study. BMJ 2000; 320:1246-50.

20. Grant RW, Altschuler A, Uratsu CS, et al. Primary care visit preparation and communication for patients with poorly controlled diabetes: A qualitative study of patients and physicians. Prim Care Diabetes 2017;11:148-53.

21. Rodriguez HP, Anastario MP, Frankel RM, et al. Can teaching agenda-setting skills to physicians improve clinical interaction quality? A controlled intervention. BMC Med Educ 2008;8:3.

22. Beverly EA, Ganda OP, Ritholz MD, et al. Look who's (not) talking: Diabetic patients' willingness to discuss self-care with physicians. Diabetes Care 2012;35:1466-72.

23. Grant RW, Pabon-Nau L, Ross KM, Youatt EJ, Pandiscio JC, Park ER. Diabetes oral medication initiation and intensification: Patient views compared with current treatment guidelines. Diabetes Educ 2011;37:78-84.

24. Landon BE, Gill JM, Antonelli RC, Rich EC. Prospects for rebuilding primary care using the patientcentered medical home. Health Aff (Millwood) 2010; 29:827-34.

25. Wagner EH, Glasgow RE, Davis C, et al. Quality improvement in chronic illness care: A collaborative approach. Jt Comm J Qual Improv 2001;27: 63-80.

26. Bodenheimer T, Laing BY. The teamlet model of primary care. Ann Fam Med 2007;5:457-61. 